\title{
Secured Question Paper Management System
}

\author{
S. M. Tawhidur Rahman, Md. Nashif Iftekhar, Rashedul Alam, S. M. Raihan Gafur and Dip Nandi
}

\begin{abstract}
The examination is one of the essential parts of the student's life. After learning from an institution, the students must attend and pass various types of examinations to get their certificates. In this process, sometimes students try to pass the examination by answering the leaked questions. From the beginning of making the question papers to delivering them to the students is now at stake in the existing question management system due to question leakage. So, the traditional way of managing the question papers needs to be changed so that it can stop the leakage of question papers. To secure the question papers and making a trustworthy, physical existence free, and affordable a system is proposed in this paper. To design this model, we have used the concept of Blockchain, Digital Signature, Randomization, OTAC.
\end{abstract}

Index Terms-Blockchain; Digital Signature; Hash; Encryption; Decryption; OTAC; Randomization

\section{INTRODUCTION}

$\mathrm{T}$ HE examination is one of the essential aspects of the education system. It evaluates the understanding, skill, knowledge, physical fitness, or aptitude of students and forces them to study. However, Question Paper Leaking of the examination can cause the fairness issues in the examinations. Each and every year, we hear news about postponed/canceled exams due to paper leakages throughout the world from

S. M. Tawhidur Rahman completed B. Sc in Computer Science and Engineering (CSE) from American International University-Bangladesh

Dhaka, Bangladesh

Email: tawhidurrahman.work@outlook.com

Md. Nashif Iftekhar completed B. Sc in Computer Science and Engineering (CSE) from American International University-Bangladesh

Dhaka, Bangladesh

Email: nashififtekhar@gmail.com

Rashedul Alam completed B. Sc in Computer Science and Engineering (CSE) from American International UniversityBangladesh

Dhaka, Bangladesh

Email: ra shed@hotmail.com

S. M. Raihan Gafur completed B. Sc in Computer Science and Engineering (CSE) from American International University-Bangladesh

Dhaka, Bangladesh

Email: raihan.gafur.49@gmail.com

Dip Nandi is an Associate Professor and Director of Faculty of Science and Technology in American International UniversityBangladesh (AIUB).

Dhaka, Bangladesh

Email: dip.nandi@aiub.edu entrance examination to public examination. The situation in developed countries is getting worse [1-4]. This aspect will create a negative impact on students and will demoralize the growth of society.

In China, a teacher at the Dalian University of Technology was accused of leaking a math test ahead of China's annual postgraduate entrance exam [5]. In Egypt, French language exam papers were posted on Facebook half an hour after the start of the exam [6], and a version of the Arabic test, was leaked on the first day of the Thanaweya Amma exam [7]. A teacher in Vietnam was accused of leaking questions of a final examination to a neighbor's son [8]. A number of cases related to paper leakage have occurred in Pakistan [9-13], India [14-16] and Nepal [17], [18], respectively. In Bangladesh, public examination questions were leaked [1921]. In Korea, another high school teacher was accused of leaking English exam questions [22]. In the United Kingdom, Brighton Hove and Sussex Sixth Form College canceled the A-level physics exam, and students were sent home after discovering the question paper leak on social media [23]. ACT Inc, the most popular U.S. college entrance exam maker, said Thursday that it had canceled the ACT exam scheduled for Saturday at some of its international test centers due to a breach of the test materials [24]. The question paper was also leaked at the University of South Africa (Unisa) [25].

The above incidents show that question paper leakage happens not only within the developing and underdeveloped countries but also in developed countries. We must not forget, once an unjust examination happens, it may change the fate of tens of thousands of young people. Before the cases of leakage increase, we need to take action to secure question papers! And something needs to be done to restore the faith of society in the education system and to place it in educated, skilled hands. The sooner we take action, the sooner everything falls in place! COVID-19, ongoing global pandemic due to Corona virus caused several changes in the education sector of the world. Institutions like school, colleges and universities resume the classes and exams in different online platforms. Now, in order to establish a proper systematic approach of taking examination by securing the question papers may ensure quality of the education. The proposed model will help to fulfil the desire.

The individual parts of the paper are arranged as follows: the related works is outlined in section 2. The segment addresses the various research papers related with securing question papers management. In Section 3, after analyzing different papers our proposed solutions are covered in detail. Section 4 states the system architecture. The section shows step by step systematic approach of the system. Section 5 
shows an overall review along with performance and security issues, comparisons between our proposed model and other existing models. Finally, with potential research directions, section 6 draws a conclusion.

\section{RELATED WORKS}

Question paper leaking creates a phenomenal impact on society. Some models and schemes are proposed and described in some research work to solve this unwanted problem, s. One of them is described as a system using automatically generated Multiple Choice Questions (MCQ) with the help of Artificial Intelligence (AI) [26]. This program includes several modules for courses, user and request management, request classification, question entry, document generation, and document management [26]. The user will specify the subject matter, the type of question, and the difficulty level [26].

Another system called Automatic Question Paper Generator deals with the selection, sorting, and management of a large number of questions relevant to various groups about specific types of levels for all the subjects [28]. The shuffling algorithm of the system means the randomization technique is used to provide a solution to the mentioned problem avoiding the repetition of the questions in the examination [28]. Automatic Question Paper Generator is used as special software that is useful for schools, institutes, publishers, and test paper makers who want to have a vast database of questions and often easily generate test papers.

A systematic way, "Randomized Question Paper Generation System," is considered to be software that is mainly used in schools, universities, etc., to generate and check paper setters who mainly want to provide a huge record of questions in the question paper and also provides comfort [33]. It primarily supplies the assembly, classification, and coordination of queries regarding various degrees of intensity from empirical as well as non-scientific subjects relevant to several groups [33]. It presents, in particular, the practices of procedures in the Randomized Generator Question Paper System (RGQS) to overcome the above-described problem [33]. The main part of the procedures is to provide a random method in the System Group so that different sets of questions could be produced mainly without repetition and duplication [33].

This paper presents a new smart education scheme, by using the blockchain concept to share questions [38]. To shuffle questions, they used a two-phase encryption technique using timestamp, salt hashing, smart contract and a technique of random algorithms [38].

Along with these models, there are also different types of management systems proposed, and they digitally stored the exam-relevant information, and then the exam management system is implemented [27]. To obtain the required degree of safety at any examination point, a cryptographic scheme has to be implemented [27]. It defines six security criteria, such as authenticity, anonymity, correction, confidentiality, receipt, identification of the copies [27].

Considering geographical zones and different exam centers, online question paper uploading, and downloading from different locations, this paper proposed an exam management system [29]. In this proposed model, question papers are made available online in different geographical zones consisting of several examination centers where they can only be downloaded after the time stipulated [29].

This paper provides a Blockchain-based framework for conducting and assessing academic examinations in a peer-to peer manner with auto-generating certificates upon successful completion of the examination. [30] The proposed framework for conducting a decentralized examination uses blockchain to enhance the evaluation and maintenance of examination records in such a way that the records are more accurate, reliable, and secure in accordance with the current examination system [30]. To make the test as accurate as possible, the hash-digest of every question presented and any question answered is stored directly upon this blockchain [30]. A variant of the voting-based consensus process is used, named Delegated Stake Proof, and each operation is documented as a blockchain transaction [30].

A webbased, stable, automated question paper generation system that is robust to question paper leakage as it replaces the conventional paper generation process [31]. The suggested program would provide a smart question paper generator to produce questions within seconds [31]. This initiative includes two processes:

(i) the production phase of the Question Bank and

(ii) the creation process of the Question Paper [31].

Not only digitally but also using physical accessories, the question papers can be secured. An electronic protection system with high security to avoid paper leakage in any examinations [32]. The question papers will be shipped in an electronically locked box to the test centers [32]. The box can be opened after a predefined date, time, and only by an authorized person using an RFID card [32]. Otherwise, a message will be sent to a predefined phone number. These boxes are password protected, which are sent by the Exam Controller [32]. The box will open through an electromagnetic lock, if the date, time, and password match. A buzzer is used in this system for any unauthorized interference [32].

Another solution is proposed physically-based on the fingerprint for Authentication and also uses a number lock feature, GPS Kit, to provide improved security and access control [34]. It uses a sensor to monitor and avoid interference with automatically send warning messages [34]. Tracking the machine Place that has been introduced with GPS and sends the connection to the control room using GSM [34]. Also, Solar panels are used to supply the system with electricity [34].

Moreover, a lightweight and portable solutions with a variety of designs and implemented to inspect paper leakage security system, which is a highly protected ARM processorbased device [35]. The system uses GSM technology, RFID module, key-pad, and electromagnetic lock [35].

From the related works, it is observed that there are some limitations in their solutions. Firstly, no traceability for leakage questions is described. Though the system is designed with high security, it is not mentioned about finding out the 
responsible person if the question paper is leaked. Secondly, the question papers are printed too early before the exam which increases the chance of leaking the questions by the persons related to printing. Third and finally, Artificial Intelligence (AI) based systems cannot differentiate whether the questions are right or not.

\section{PROPOSED SOLUTIONS}

To solve those problems in the existing systems, we have proposed a blockchain based question paper management system along with other technologies to secure the question papers. To demonstrate and explain the model, we have discussed the system in two parts, one is the technologies we used in this system, and another part is system architecture.

In this section we will discuss the main technologies like Blockchain, Hashing, OTAC, Digital Signature and others. Blockchain is a data storing system that is distributed and replicated among the network nodes that participate [38].

It has begun to attract attention from a wide range of individual sectors, including banking, medical departments, the supply chain in industries, land properties, personal data, education sectors, finance industry, public service sectors and delivery of digital content etc. [40-45]. When a transaction takes place in the network, the transaction must have a validation process called the consensus mechanism [38]. Transaction means adding blocks, sending, or receiving data from the nodes to nodes. Those who perform the method of consensus are called miners, and they have to execute a computationally complicated puzzle called hashing [42].

Hashing is a process of converting a key into another value which cannot be converted back to the original key. After that, a block containing the transaction is attached to the chain. Every block holds the preceding block's hash. Therefore, it creates a chain of blocks, and it is called the blockchain. From all the blocks, the first block of the blockchain is called block genesis [38]. As this block has no previous hash block, it contains 0 or a value that is predefined by the system.

In most sections of Application on the blockchain, block genesis is hardcoded [38]. If anyone does make some changes in the blockchain, then the hash of that block changes in the transaction, which breaks the Blocks. In order to make the changes, a user must then mine other participant's nodes in the chain, and it is very difficult. So, without mining the hash, this is impossible to add any blocks into the system for QS, QM or for anyone. Every user has two keys in the blockchain, 1) the public key and 2) the private key. Public key will be available for everyone but the private key or secret key will be kept secret [42].

Digital Signature is one of the useful and efficient features of the blockchain and it ensures the system's authentication, credentials, privacy, and trust [27]. The digital signature is generated in the values of cryptography that rely on data and data sender [36]. So, the digital signature is used in the various transactions of data and recording data [27], [37], [38] With these various transactions, it also ensures security in webbased services [36], [39].

We used Digital Signature to secure the questions during transition and the authentication of the questions. Also, the question setters or question moderators cannot deny that these questions haven't been sent by them. Then, after sending the questions, it cannot be modified by the sender. OTAC stands for One Time Authorization Code. One time authorization code (OTAC) refers to a code valid for authenticating a user's identity for a single session only. Services such as online banking or ATM machines are authenticated in a very safe manner [46]. To authenticate the QSs and QMs we have used the OTAC. OTAC will generate a one time authorization code for the QSs and QMs. So, if the question setter wants to store and submit the questions then he/she must pass the OTAC verification. After that the QSs and QMs can upload the questions in the system [46].

\section{SYSTEM ARCHITECTURE}

Exam Controller (EC) will choose and invite Question Setters (QS) and Question Moderators (QM) to prepare the questions. If the number of questions needed for the exam is 100, then total 3000 questions needed for generating the final question set. So there must be at least 30 QSs. To login into the system the Question Setters (QS) and Question Moderators (QM) must verify the OTAC sent from the system. This will grant the access every QS and QM into the system. After successfully, login to the system, everyone will get a public key, private key and EC will get an additional secret key as shown in Fig. 10.

Step 1: Each QS will digitally sign the question set of 100 questions using the public key of EC before submission as shown in Fig. 1. Then, the question set EC receives from the QSs will be decrypted using the private key of the EC. After that, the EC will digitally sign 3000 questions using secret key and will store the questions in separate 30 blocks of blockchain.

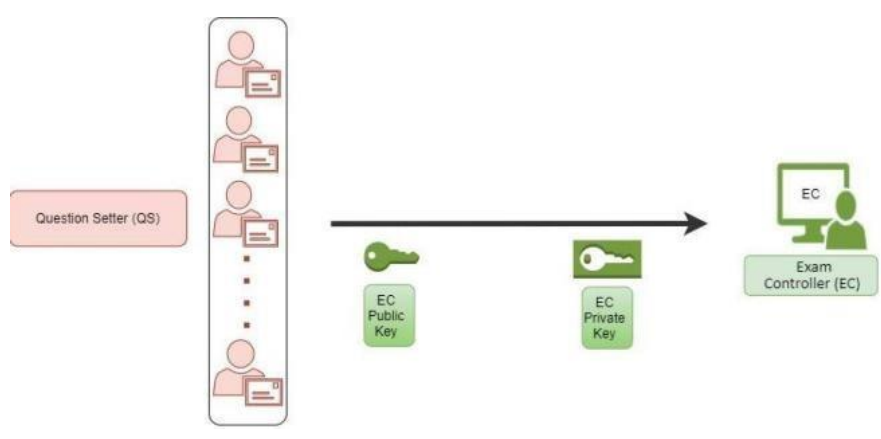

Fig. 1.

Step 2: Then the questions from 30 blocks will be fetched. EC will decrypt the data using the secret key as shown in Fig. $2 \& 3$. The system will perform randomization to remove 20 questions from each set and then EC will digitally sign these set of 80 questions and store it in another separate 30 blocks of the blockchain. 

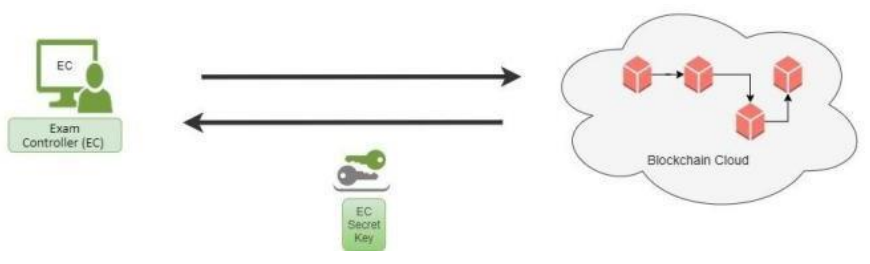

Fig. 2.
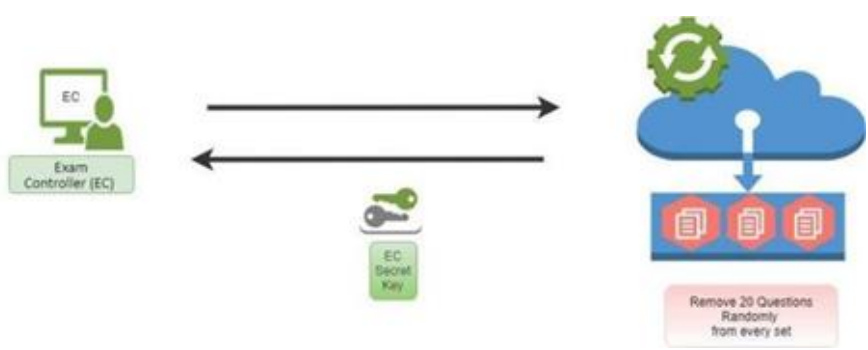

Fig. 3.

Step 3: In the next step, The EC will fetch and decrypt every set of questions using his secret key. After that, total questions will be divided based on the number of moderators chose by the EC. The EC will digitally sign each question sets using the public keys of the moderators respectively and will send it to the moderator for moderation as shown in Fig. 4 \& 5 .
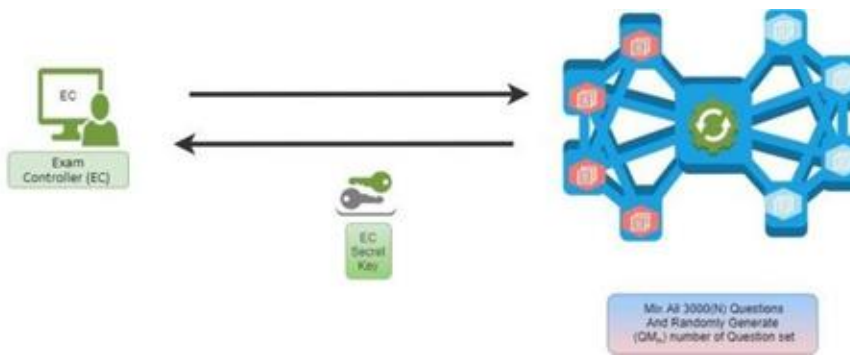

Fig. 4.

Step 4: After that the QMs will decrypt their question sets using their private key and perform question moderation. After, the moderation the questions will be digitally signed using the public key of EC. EC will receive and decrypt the question sets by using his private key as shown in Fig. 5. He will again digitally sign the question sets using his secret key and store each set of questions in distinct blocks of blockchain.

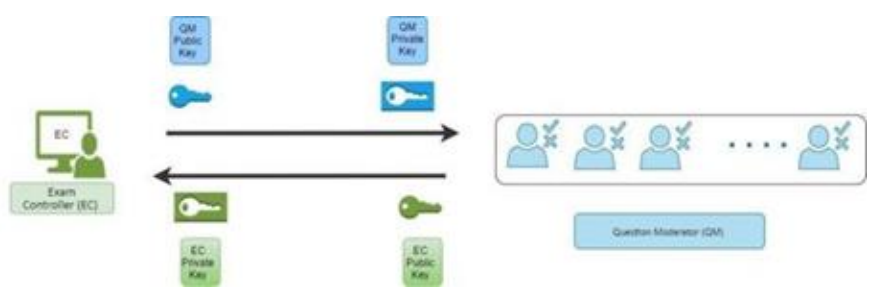

Step 5: Then, the EC will again fetch and decrypt the question sets using his secret key to get all the questions from every blocks as shown in Fig. 6. Now, total 2000 questions will be chosen randomly as shown in Fig. 7. The questions will be stored in a single block after digitally signed by EC's secret key as shown in Fig. 8.
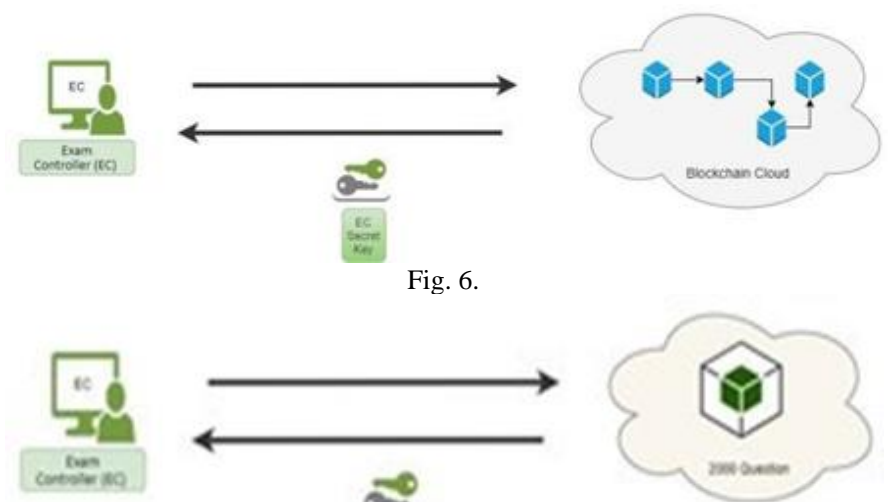

Fig. 6.

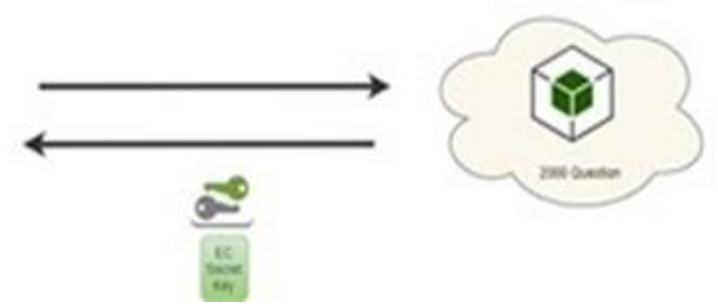

Fig. 7.
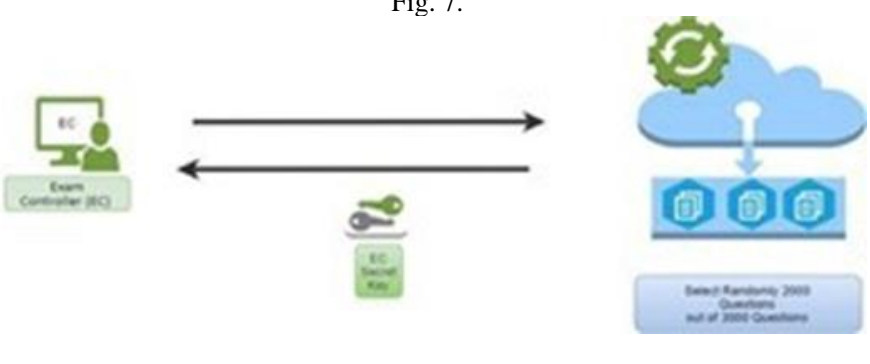

Fig. 8.

Step 6: In the day of exam, the EC will fetch and decrypt the questions using the secret key just before exam starts (5-10 minutes). Now, finally the system will choose 100 questions for the exam randomly. These final questions will be sent to the printers connected with the system in classrooms of every exam centers, 5-10 minutes before the exam is started. The printers will print all the questions for the examinee as shown in Fig. 9.

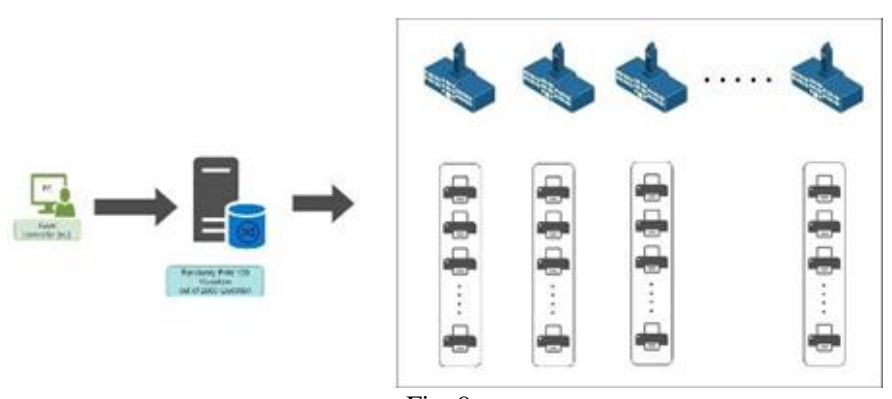

Fig. 9.

Fig. 5. 


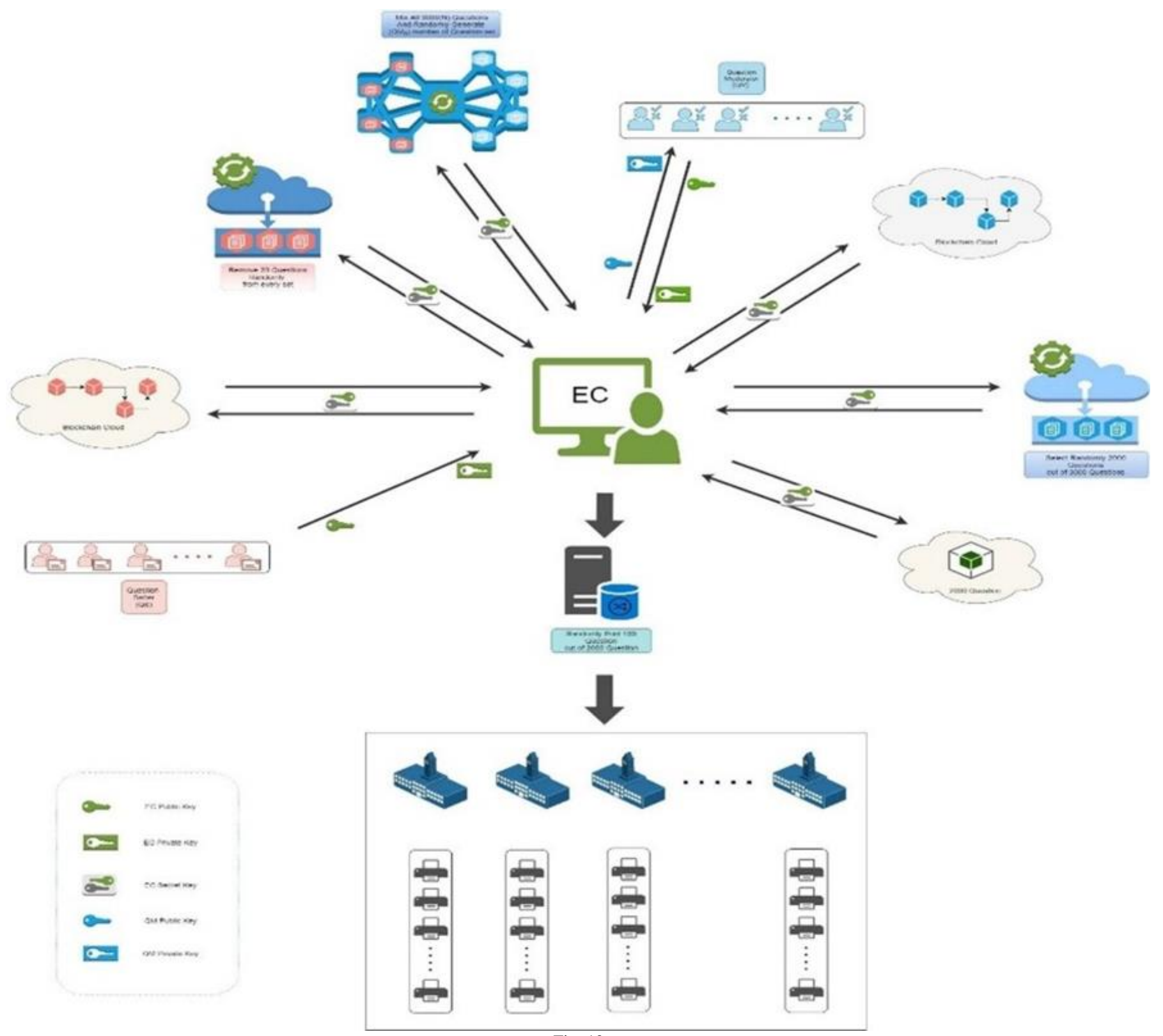

Fig. 10.

\section{DISCUSSION}

Properly securing question papers is difficult, but to ensure a fair examination the question papers must be secured. To provide a secure system, we have used some technologies that we mentioned earlier in this paper. Though the system is designed with strong security, there might still be a chance of leaking questions by the associated persons. So, to trace the person, we will match the leaked question paper with the stored question papers in the blockchain. As the group of questions is kept secured using a digital signature, we can identify the responsible QS or QM. If all the questions are leaked, then EC will be responsible for the leakage because only EC would have the access to see all the questions.
The questions will be selected randomly and it is quite impossible to guess the final questions from the large number of questions to leak the questions. There are no physical printing options or any physical documenting options where the questions could be leaked before the examination. Moreover, the questions will be ready just 5-10 minutes before the exam starts. The printers will print the questions in front of the invigilators. It reduces the chance of leaking the questions massively and this won't be helpful to solve the questions in such a small time. The system uses human involvement to set the questions instead of Artificial Intelligence (AI) which cannot detect whether the question is right or wrong (spelling mistakes, arithmetic, logical, graphical problems) in the questions. As we are using randomization technique in our system to select the final questions from a large quantity of the questions, it will ensure a standard question. 
The significant side of the question paper management systems are securing question papers in different ways but one of the important aspects, tracing the person or people doing leakage of questions is absent in the models [26-38]. In our proposed model we represented a systematic approach to find out the responsible person. Another obstacle of securing questions is the existence of physical documenting which can be leaked [32], [34]. So, to solve this problem there is no physical documentation in our system and the only physical existence of the questions will be disclosed 5-10 minutes before the exam starts and the copies will be printed in the rooms of the examination centres. Artificial Intelligence can be used in many ways but the problem may arise when AI cannot differentiate the questions correctness [26-28]. A small change of symbol can change the whole question. For this problem, the proposed model shows the use of human involvement for making the questions and the model used the randomization technique to make the question papers more standard for the examinees.

\section{CONCLUSION}

In this paper, we proposed a blockchain-based question paper management system to secure the question papers from leaking. In this model or scheme, we used some well known technologies to secure question papers as well as to trace the person who is responsible for the leakage. We used the digital signature to ensure the question papers authenticity. The involvement of question setters and moderators in making the questions and the use of randomization technique makes the question papers more standard. Moreover, there is no place for physical documenting before starting the exam. Therefore, the proposed model is better in terms of the security and the feature of tracing the responsible person of question papers leakage made the model unique from others systems to secure question papers [26 - 38]. Due to shortage of time and resources, we could not implement the proposed system though we are hopeful to implement the system in future.

\section{REFERENCES}

[1] S. Heyneman, "Uses of examinations in developing countries: Selection, research, and education sector management," 1987 International Journal of Educational Development, vol. 7, no. 4, pp. 251-263, Available: 10.1016/0738-0593(87)90023-x.

[2] R.A. Olatoye, "Checking the menace of examination malpractice: A call for more teaching and learning in schools," 2013.

[3] A. Emiloju and C. Adeyoju, "The Challenges of Maintaining the Integrity of Public Examinations in Nigeria: The Ethical Issues", International Education Studies, vol. 5, no. 2, 2012. Available: 10.5539/ies.v5n2p18.

[4] Roy, N.R, Nahar, N.S and Sharmin, R, "'Question leakage in public examinations: Process, reason and way forward' Transparency International Bangladesh (TIB)", $2015 \quad$ Available: https://www.tibangladesh.org/beta3/images/2015/es \ffs \_qpl\15\_en.pd f.

[5] Guo, J., 'Chinese postgraduate entrance exam leaked?', SupChina, 2017 [online].

Available: https://supchina.com/2017/12/27/chinesepostgraduate-entrance- exam-leaked/ [Accessed: 17 August 2020].

[6] Al-Youm, A., 'French language exam papers leaked on Facebook', Egypt Independent, 2017 [online]. Available: https://egyptindependent.com/french-examsleaked/

[8] 'Vietnam teacher leaks test questions to neighbor as 'return of favor", Tuoi Tre News, 2017

[online]. Available: https://tuoitrenews.vn/education/41079/vietnavietnamteacher- leaks-test-questions-to-neighbor-as-return-offavor [Accessed: 17 August 2020].

[9] Dogar, A. and Javaid, R., 'Four major WhatsApp groups involved in leaking papers traced, Geo News', 2017 [online]. Available: https://www.geo.tv/latest/14093011th-in-line-Physics- supplementary-paper-leaked-inKarachi [Accessed: 17 August 2020].

[10] 'Exam season fiasco: papers leaked, students cheating in Sindh classrooms', Geo News, 2017 [online]. Available: https://www.geo.tv/latest/139515-Exam-season-fiascopapers- leaked-students-cheating-in-Sindh-classrooms

[Accessed: 17 August 2

[11] Aslam, S., 'Racket involved in MDCAT paper leak', International The News, 2017 [online]. Available:

https://www.thenews.com.pk/print/234932-Racketinvolved-in- MDCAT-paper-leak [Accessed: 17 August 2020].

[12] 'Physics paper leaked just before exams', Samaa TV, 2017 [online]. Available: https://www.samaa.tv/news/2017/05/physics- paperleaked-just-before-exams/ [Accessed: 17 August 2020].

[13] 'Who is leaking CSS exam questions?', Dunya News, $2017 \quad$ [online]. Available: http://dunyanews.tv/en/Pakistan/375604-Who- is-leakingCSS-exam-questions [Accessed: 17 August 2020].

[14] 'Recruitment exam paper leak: Army begins probe; exams cancelled across India', New Indian Express, 2017 [online]. Available: https://www.newindianexpress.com/nation/2017/feb/26/recruitmen texam-paper-leak-army-begins-probe-exams-cancelled-across- india1575035.html [Accessed: 17 August 2020].

[15] 'AIIMS MBBS 2017 entrance test paper leaked, says Vyapam whistle-blower Anand Rai', Hindustan Times, 2017 [online]. Available: https://www.hindustantimes.com/india-news/aiims- mbbs-entrancetest-paper-leaked-says-vyapam-scam-whistle- blower-anand-rai/storytuPKqb5vIXsbKy7CGvSfAP.html [Accessed: 17 August 2020].

[16] 'NEET 2017 paper leak: Racket kingpin arrested in Delhi', India Today, 2017 [online]. Available:

https://www.indiatoday.in/education-today/news/story/neet-2017paper-leak-976849-2017-05-13 [Accessed: 17 August 2020].

[17] '10 held on question leakage charge', The Kathmandu Post, 2017 [online]. Available:

https://kathmandupost.com/national/2018/01/07/10-held-on- questionleakage-charge [Accessed: 17 August 2020].

[18] 'Papers might have been leaked, police tell IoM', The Kathmandu Post, 2017 [online]. Available: 
https://kathmandupost.com/national/2017/11/06/papers-might- havebeen-leaked-police-tell-iom [Accessed: 17 August 2020].

[19] 'Man jailed for leaking questions in Rajshahi', The Daily Star, 2018 [online]. Available: https://www.thedailystar.net/country/man-jailed-for-higher- secondarycertificate-hsc-examination-question-paper-leaking-in- rajshahi1574581 [Accessed: 17 August 2020].

[20] 'SSC question leaked again', Prothom Alo, 2018 [online]. Available: https://en.prothomalo.com/bangladesh/SSC-question- leakthis-time-in-Manikganj [Accessed: 17 August 2020].

[21] 'CID: Medical, dental admission test question papers were leaked from DGHS press', Dhaka Tribune, 2020 [online]. Available: https://www.dhakatribune.com/bangladesh/crime/2020/07/23/cidmedical-dental-exam-question-papers-leaked-from-dghs-press [Accessed: 17 August 2020].

[22] P. Si-soo, 'Teacher accused of leaking test questions to private tutor', The Korea Times, 2020 [online]. Available: http://www.koreatimes.co.kr/www/nation/2017/11/251 _239889.ht $\mathrm{ml}$ [Accessed: 17 August 2020].

[23] R. Ardehali, 'Hundreds of students are sent home after A-level physics exam is stolen and shared on social media', Daily Mail, 2017 [online]. Available:

https://www.dailymail.co.uk/news/article-4534118/Hundreds- studentssent-home-test-paper-leaked.html [Accessed: 17 August 2020].

[24] J. McCrank, 'ACT cancels some college entrance exams after test leak'. Reuters, 2017 [online]. Available: https://www.reuters.com/article/us-usa-college-cheating/act- cancelssome-college-entrance-exams-after-test-leak- idUSKCN1BI29P [Accessed:: 17 August 2020].

[25] A. Chothia, 'Unisa and SAPS investigate leaked examination question papers', The South African, 2019 [online]. Available: https://www.thesouthafrican.com/news/unisa-investigates-leaked-examquestion-papers-november-2019/ [Accessed: 17 August 2020].

[26] G. Cen et al., "A implementation of an automatic examination paper generation system," 2010 Mathematical and Computer Modelling, vol. 51, no. 11-12, pp. 1339-1342, Available: 10.1016/j.mcm.2009.11.010

[27] J. Castella-Roca, J. Herrera-Joancomarti and A. Dorca-Josa, "A secure e-exam management system," 2006 First International Conference on Availability, Reliability and Security (ARES'06),

Vienna, Austria, pp. 8 pp.-871. doi: 10.1109/ARES.2006.14

[28] A. Khairnar, B. Jadhav, R. Birhade and P. Patil, "Automatic Question Paper Generator," 2017 International Journal For Technological Research In Engineering, vol. 4, no. 9, pp. 2347- 4718

[29] M. Alam, M. Asad and M. Mondal, "An Online Examination Management System for Geographically Dispersed Test Centres to Prevent Question Leakage: A Case Study of Bangladesh," 2017 Journal of Scientific Research and Reports, vol. 16, no. 5, pp. 1-11, Available: $10.9734 /$ jsrr/2017/37178.

[30] R. Acharya and S. Binu, "Blockchain based examination system for effective evaluation and maintenance of examination records," 2018 International Journal of Engineering \& Technology, vol. 7, no. 26, p. 269, Available: 10.14419/ijet.v7i2.6.10781.

[31] M. Ahamed, "Development of a web-based question bank for automated question paper generation", 2019.

[32] S. Gaikwad, N. Kenjale, A. Bagade, B. Shiragapur and U. Scholar, "Electronic Protection for Exam Paper Leakage," 2016
International Journal of Engineering Science, Available: $10.4010 / 2016.857$.

[33] V. Hegde, S. D and L. S, "Randomized Online Question Paper Generation through SQL query and JEE," 2019 International Journal of Innovative Technology and Exploring Engineering (IJITEE), vol. 8, no. 8 , pp.1438-1442.

[34] M. Imran, A. Uddin, F. Rafath, M. Osman, A. Sultana and K. Srikanth, "Real Time Application of Advanced Exam Paper Leakage Detection and Alert System with Theft Protection," 2020 4th International Conference on Trends in Electronics and Informatics (ICOEI)(48184), Tirunelveli, India, 2020, pp. 421-427. doi: 10.1109/ICOEI48184.2020.9142950

[35] P. Nalajala, P. Madhuri, M. Bhavana, B. Godavarthi, and G. Reddy, "RFID based security for exam paper leakage using electromagnetic lock system," 2017 International journal of pure and applied Mathematics, vol. 117, no. 20, pp.845-852.

[36] I. Nurhaida, D. Ramayanti and R. Riesaputra, "Digital signature \& encryption implementation for increasing authentication, integrity, security and data non-repudiation," 2017 International Research Journal of Computer Science (IRJCS), vol. 4, no. 4, pp.4-14

[37] M. A. Sadikin and R. W. Wardhani, "Implementation of RSA 2048-bit and AES 256-bit with digital signature for secure electronic health record application," 2016 International Seminar on Intelligent Technology and Its Applications (ISITIA), Lombok, 2016, pp. 387392, doi: 10.1109/ISITIA.2016.7828691

[38] A. Islam, M. Kader, and S. Shin, "BSSSQS: A Blockchain- Based Smart and Secured Scheme for Question Sharing in the Smart Education System," 2019 Journal of information and communication convergence engineering, vol. 17, no. 3, pp.174- 184.

[39] K. Vijayakumar and C. Arun, "Continuous security assessment of cloud based applications using distributed hashing algorithm in SDLC," 2017 Cluster Computing, vol. 22, no. 5, pp. 10789-10800, Available: 10.1007/s10586-017-1176-x.

[40] G. Zyskind, O. Nathan and A. '. Pentland, "Decentralizing Privacy: Using Blockchain to Protect Personal Data," 2015 IEEE Security and Privacy Workshops, San Jose, CA, 2015, pp. 180-184, doi: 10.1109/SPW.2015.27.

[41] J. Kishigami, S. Fujimura, H. Watanabe, A. Nakadaira and A. Akutsu, "The Blockchain-Based Digital Content Distribution System," 2015 IEEE Fifth International Conference on Big Data and Cloud Computing, Dalian, 2015, pp. 187-190, doi: 10.1109/BDCloud.2015.60.

[42] A. Razzaq et al., "Use of Blockchain in Governance: A Systematic Literature Review," 2019 International Journal of Advanced Computer Science and Applications, vol. 10, no. 5, Available: 10.14569/ijacsa.2019.0100585.

[43] S. Ølnes and A. Jansen, "Blockchain Technology as s Support Infrastructure in e-Government," Lecture Notes in Computer Science, pp. 215-227, 2017. Available: 10.1007/978-3-319-64677-0_18.

[44] A. K. Shrivastava, C. Vashistth, A. Rajak and A. K. Tripathi, "A Decentralized Way to Store and Authenticate Educational Documents on Private Blockchain," 2019 International Conference on Issues and Challenges in Intelligent Computing Techniques (ICICT), GHAZIABAD, India, 2019, pp. 1-6, doi: 10.1109/ICICT46931.2019.8977633.

[45] A. Azaria, A. Ekblaw, T. Vieira and A. Lippman, "MedRec: Using Blockchain for Medical Data Access and Permission Management," 2016 2nd International Conference on Open and Big Data (OBD), Vienna, 2016, pp. 25-30, doi: 10.1109/OBD.2016.11. 
[46] F. Aloul, S. Zahidi and W. El-Hajj, "Two factor authentication using mobile phones," 2009 IEEE/ACS International Conference on Computer Systems and Applications, Rabat, 2009, pp. 641-644, doi: 10.1109/AICCSA.2009.506

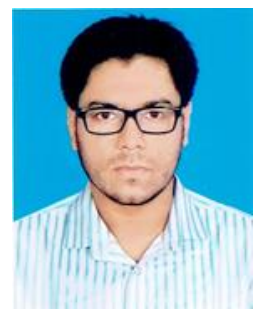

S. M. Tawhidur Rahman has got his Bachelor of Science (BSc) in Computer Science \& Engineering (CSE) at American International University - Bangladesh (AIUB) from the year 2016 to 2020 . His current research interest is in the field of Blockchain, machine learning and modern world problems.

basic applications of Mathematics in

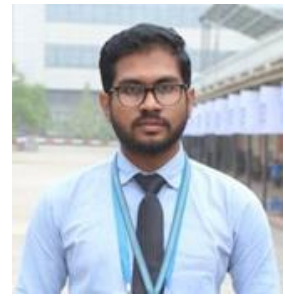

Md. Nashif Iftekhar has completed his Bachelor of Science (BSc) in Computer Science \& Engineering (CSE) at American International University - Bangladesh (AIUB) from the year 2016 to 2020 . He

was the Vice President for year 2020 of AIUB Computer Club (ACC). He has an enthusiasm over the research field of Blockchain, Cyber Security, Internet of Things, Encryption Algorithms and Modern System Architecture Designing.

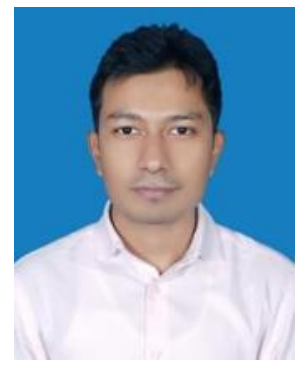

Rashedul Alam has got his Bachelor of Science (BSc) in Computer Science \& Engineering (CSE) at American International University - Bangladesh (AIUB) from the year 2016 to 2020 . He has an enthusiasm over the research field of Blockchain, Internet of Things, Supply Chain Management and Decentralized Application.

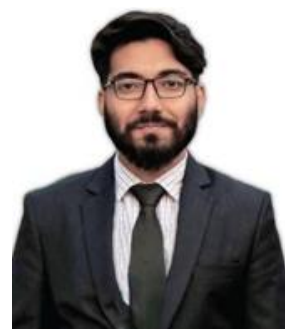

S. M. Raihan Gafur has completed his Bachelor of Science (BSc) in Computer Science \& Engineering (CSE) at American International University - Bangladesh (AIUB) from the year 2016 to 2020 . He was selected five times in the

Dean's List of Honor from Faculty of Science and Technology, AIUB and also achieved academic scholarship for his meritorious result in his BSc. He was the president for year 2020 of AIUB Computer Club (ACC). He is highly interested in doing research in CyberPsychology, Human Computer Interaction and User Experience, Machine Learning, Blockchain, Encryption Algorithms and Network Security.

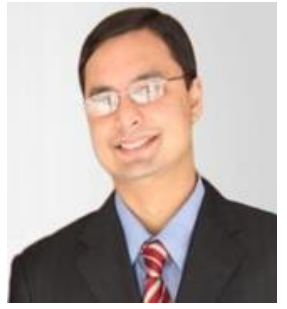

Dip Nandi Has completed his Master Degree on Information Systems from The University of Melbourne, Australia in 2009. Later he finished his Doctor of Philosophy $(\mathrm{PhD})$ in Computer Science from RMIT University Melbourne, Victoria, Australia.

Dr. Nandi is the current Associate Professor and Honorable Director of Faculty of Science \& Technology (FST), at American International UniversityBangladesh (AIUB). $\mathrm{He}$ is a former lecturer at RMIT University Melbourne, Australia from the year 2010 to 2012. Dr. Nandi has a vast range of research activities and contributions in various filed of Computer Science and Multidimensional researches. His profound knowledge over many leading domains and areas include the concept of Algorithmic Design, Software Engineering model \& process, Machine learning, Data Warehousing, E Learning are mostly notable. Dr. Dip Nandi also has his Contributions in Alzheimer's disease and Dementia detection using Neural Networks. The education-based researches are also his area of expertise. 